\title{
Eleven-year follow-up of cardiac paraganglioma in a patient with SDHD C11X gene mutation
}

\author{
Anna M Michałowska' ${ }^{1}$ Jarosław B Ćwikła ${ }^{2,3}$, Marek Konka ${ }^{4}$, Agnieszka Kolasińska-Ćwikła ${ }^{5}$, \\ Andrzej Januszewicz ${ }^{6}$, Ilona Michałowska ${ }^{7}$, Mariola Pęczkowska ${ }^{6}$
}

'National Institute of Cardiology, Warszawa, Poland

${ }^{2} S c h o o l$ of Medicine, University of Warmia and Mazury, Olsztyn, Poland

3Diagnostic and Therapy Center "Gammed", Warszawa, Poland

${ }^{4}$ Congenital Heart Diseases Department, National Institute of Cardiology, Warszawa, Poland

${ }^{5}$ Maria Sklodowska-Curie National Research Institute of Oncology, Warszawa, Poland

${ }^{6}$ Department of Hypertension, National Institute of Cardiology, Warszawa, Poland

'Department of Radiology, National Institute of Cardiology, Warszawa, Poland

Correspondence to: Ilona Michałowska, MD, PhD, Department of Radiology, National Institute of Cardiology, Alpejska 42, 04-628 Warszawa, Poland,

phone: +48223434167, e-mail: imichalowska@ikard.pl Copyright by the Author(s), 2021 Kardiol Pol. 2021; 79 (11): 1276-1277; DOI: 10.33963/KP.a2021.0085 Received: July 1, 2021 Revision accepted: August 12, 2021 Published online: August 12, 2021
A 25-year-old asymptomatic male patient with confirmed SDHD C11X gene mutation (paraganglioma/pheochromocytoma syndrome 1 [PGL1] syndrome) was admitted to the Department of Hypertension at the National Institute of Cardiology in Warsaw for screening for paragangliomas and pheochromocytomas. PGL1 syndrome was previously diagnosed in his two brothers with hormonally active paragangliomas and pheochromocytomas and in his asymptomatic father, who refused further examinations. The clinic and ambulatory blood pressure measurements (ABPM) were within normal limits (ABPM, 112/68; 113/69; 110/64 mm Hg).

Contrast-enhanced computed tomography $(\mathrm{CT})$ of the head and neck, chest, and abdomen showed carotid and vagal paragangliomas (PGLs) (Figure 1A, B), and located on the right side in the atrioventricular groove an intracardiac mass, which was supplied by the right coronary artery (RCA) (Figure 1C, D). The assay that measured plasma concentrations of methoxycatecholamines showed an increase in methoxytyramine concentration and a slight increase in a normetanephrine concentration (methoxytyramine, $144.09 \mathrm{pg} / \mathrm{ml}$; normal value up to $30 \mathrm{pg} / \mathrm{ml}$, normetanephrine, $121.92 \mathrm{pg} / \mathrm{ml}$; normal values adjusted to age up to $118.1 \mathrm{pg} / \mathrm{ml}$ ). The level of metanephrine was normal ( $4.55 \mathrm{pg} / \mathrm{ml}$; normal values up to $88 \mathrm{pg} / \mathrm{ml}$ ). Plasma methoxycatecholamines were measured once a year during the observation period and remained stable.
Transthoracic echocardiography revealed a small spherical structure with higher echogenicity situated to the right of the coronary sinus bulging into the right atrium and mild tricuspid insufficiency with normal heart contractility (Figure 1E). The patient underwent I-123-labeled metaiodobenzylguanidine scintigraphy without any pathological reuptake while somatostatin analog scintigraphy showed active tracer accumulation in the carotid and mediastinal area (Figure $1 \mathrm{~F}-\mathrm{I}$ ). Due to the anatomical course of RCA above $P G L$, surgical resection was contraindicated. After the oncological consultation, treatment with a synthetic analog of somatostatin was started (lanreotide $120 \mathrm{mg}$ every 4 weeks intramuscularly). During 11 years of follow-up, the patient remained clinically stable with control CT, scintigraphy scans, and plasma methoxycatecholamines performed every year. The cardiac PGL size increased from $32 \times 24.5 \times 30 \mathrm{~mm}$ to $36 \times 25 \times 33 \mathrm{~mm}$ during the observation period.

PGLs are rare, usually benign extra-adrenal non-epithelial neuroendocrine neoplasms (NENs) arising from paraganglionic tissue of the parasympathetic and sympathetic nervous systems [1]. PGL can be sporadic or inherited. Herein we have presented a case of PGL1 caused by C11X SDHD gene mutation, which was found to be a Polish founder mutation [2]. The risk profile of this mutation includes multifocal lesions, often located in the head and neck, but also in the chest and 


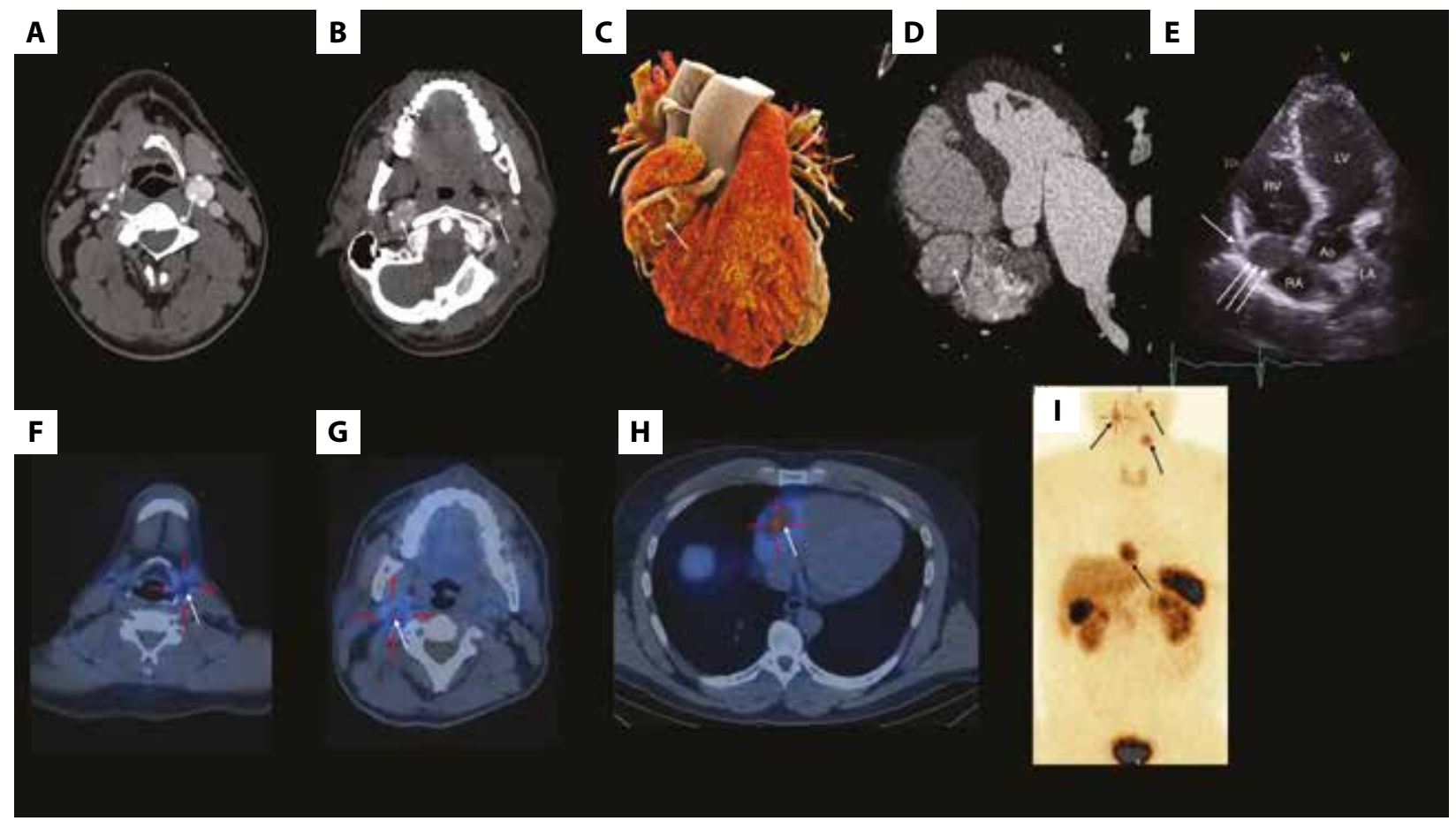

Figure 1. Control examinations. A. B. Axial contrast-enhanced CT of the neck shows carotid and vagal PGLs (white arrows). C. CT, a cinematic rendering reconstruction shows the right coronary artery running across the surface of the cardiac PGL located in the atrioventricular groove (white arrow). D. CT, multiplanar reconstruction, cardiac PGL (white arrow). E. Transthoracic echocardiography, five-chamber view. Right coronary artery - arrow, tumor — arrows. F-I. Somatostatin Receptor Scintigraphy using ${ }^{99 m}$ Tc HYNICTOC (Tektrotyd, NCBJ, Polatom, Poland). Whole-body SPECT/CT. High expression of somatostatin receptors seen in HNPs on the left side (white arrow) (F) and a HNP on the right side (white arrow) (G). Additionally, PGL in the atrioventricular groove (white arrow and red cross) (H). In MIP semi-whole body SPECT image all PGLs (black arrows). Two HNPs on the left, single HNP on the right side and the additional PGL in the atrioventricular region. Physiological uptake seen in the thyroid, liver, kidney. A very high physiological uptake seen in the gall bladder, spleen, and bladder (I)

Abbreviations: Ao, aorta; CT, computed tomography; HNP, head, and neck PGLs; LA, left atrium; LV, left ventricle; PGL, paraganglioma; RA, right atrium; RV, right ventricle

abdomen, usually extra-adrenally. The clinical manifestation of PGL is determined by local invasion of the pathological masses and/or hypersecretion of catecholamines and might have fatal consequences if undiagnosed. Head and neck PGLs are rare, usually non-secreting tumors while cardiac PGLs are even rarer $[3,4]$. Though surgical resection is a gold standard of PGLs treatment, in some cases of cardiac PGLs, heart transplantation might be necessary [5].

\section{Article information}

Conflict of interests: None declared.

Open access: This article is available in open access under Creative Common Attribution-Non-Commercial-No Derivatives 4.0 International (CC BY-NC-ND 4.0) license, allowing to download articles and share them with others as long as they credit the authors and the publisher, but without permission to change them in any way or use them commercially. For commercial use, please contact the journal office at kardiologiapolska@ptkardio.pl.

How to cite: Michałowska AM, Ćwikła JB, Konka M, et al. Eleven-year follow-up of cardiac paraganglioma in a patient with SDHD C11X gene mutation. Kardiol Pol. 2021; 79(11): 1276-1277, doi: 10.33963/KP.a2021.0085.

\section{REFERENCES}

1. Gopalakrishnan R, Ticzon AR, Cruz PA, et al. Cardiac paraganglioma (chemodectoma): a case report and review of the literature. J Thorac Cardiovasc Surg. 1978; 76(2): 183-189, indexed in Pubmed: 210330.

2. Peczkowska M, Erlic Z, Hoffmann MM, et al. Impact of screening kindreds for SDHD p.Cys $11 \mathrm{X}$ as a common mutation associated with paraganglioma syndrome type 1. J Clin Endocrinol Metab. 2008; 93(12): 4818-4825, doi: 10.1210/jc.2008-1290, indexed in Pubmed: 18826997.

3. Guichard JP, Fakhry N, Franc J, et al. Morphological and functional imaging of neck paragangliomas. Eur Ann Otorhinolaryngol Head Neck Dis. 2017; 134(4): 243-248, doi: 10.1016/j.anorl.2016.10.003, indexed in Pubmed: 27887852.

4. Mete $\mathrm{O}$, Pakbaz $\mathrm{S}, \mathrm{Cassol} \mathrm{C}$, et al. The spectrum and clinical features of paragangliomas. Lab Investig. 2018; 98: 234.

5. Neumann HPH, Young WF, Eng C. Pheochromocytoma and paraganglioma. N Engl J Med. 2019; 381(6): 552-565, doi: 10.1056/NEJMra1806651, indexed in Pubmed: 31390501. 